\title{
States Fragility Assessment Model Based on Climate Change
}

\author{
Yixuan Liang ${ }^{1, ~ a, ~ H a i l e i ~ L a n ², ~ b, ~ Y a n ~ Z h a n ~}{ }^{3, c}$ \\ ${ }^{1}$ School of Economics, Hebei University, Baoding 071002, China; \\ ${ }^{2}$ School of Cyber Security and Computer, Hebei University, Baoding 071002, China; \\ ${ }^{3}$ School of Mathematics and Information Science, Hebei University, Baoding 071002, China. \\ a982995988@qq.com, b1264191943@qq.com, ‘6662945@qq.com
}

\begin{abstract}
Various climate changes, including global warming, etc., have different impacts in different parts of the world and even lead to an increase in the fragile of social and governmental structures. Timmerman $P$ proposed the concept of vulnerability in 1981 firstly. The Fund for Peace (FFP) started publishing the annual Fragile States Index (FSI)[1] in 2005. It is widely used by researchers, educators, and governments across the world. Based on FSI, this paper adds the influence of climate change on national vulnerability, and establishes a new model defined as States Fragility Assessment Model (SFAM) by using entropy weighting method. Taking the North African country Egypt with serious climate problem as an example, SFAM combines with grey prediction to analyze the vulnerability of Egypt and predict its trend from 2019 to 2032. Finally, this paper put forward effective suggestions for the current situation that the fragility of Egypt is decreasing year by year.
\end{abstract}

Keywords: Fragile States Index, Climate Change, Entropy Weight Method, Gray Prediction Model, Egypt, MATLAB.

\section{Introduction}

With the prosperity of the global economy, the living conditions of people have been raised, people are beginning to realize the importance of climate. Increasing environmental and climatic problems are unknowingly changing the impacts of our lives and climate change, including increased droughts, shrinking glaciers, changes in the range of animals and plants, sea-level rise that vary with the region different. Just a slight change in the climate can produce unpredictable results. For example, these effects will change human lifestyles and may lead to the breakdown and collapse of social and government structures. An unstable government system may increase the country's vulnerability and put it in crisis. The instability of the country further aggravates the impact of climate change, and the greater the loss suffered by the people, the problems arising therefrom will further aggravate the international instability and form a vicious cycle. On the contrary, if the stability of the country is high, and the country has sufficient capital and ability to defend the people's lives and property, then the development of the country will be better.[1].

\section{Select Indicators}

The Fund for Peace (FFP) is a US non-profit, non-governmental research and educational institution founded in 1957. It works to prevent violent conflict and promote sustainable security. FFP started publishing the annual Fragile States Index after 2005. It is used by researchers, educators, and governments across the world. Here we get 12 indicators for assessing vulnerabilities from Fragile States Index (FSI), their types and names are shown in Table 1:

States Fragility Assessment Model not only measures the degree of vulnerability, but also the effects of climate change, we first select the above 12 indicators by Analytic Hierarchy Process and obtain eight indicators with weights in the top eight. Then, we have learned from the literature that military spending can describe the security situation of a country very well.[2] Therefore, we use the military budget as a third indicator. According to the World Bank's measure of the impact of climate change, we selected 4 indicators to characterize its impact on climate change. Finally, we got the system of vulnerability assessment including five second-level indicators and 13 third-level indicators. Because of the double attributes of some of the 13 indicators we give, such as refugees, here we only 
select the most prominent attributes of the 13 indicators to simplify and divide them into five secondlevel indicators, see the following Table 2 for details.

Table 1.12 indicators in FSI

\begin{tabular}{cc}
\hline Type & Indicators \\
\hline COHESION INDICATORS & Security Apparatus \\
& $\begin{array}{c}\text { Factionalized Elites } \\
\text { Group Grievance }\end{array}$ \\
\hline ECONOMIC INDICATORS & Economic Decline \\
& $\begin{array}{c}\text { Uneven Economic Development } \\
\text { Human Flight and Brain Drain }\end{array}$ \\
\hline \multirow{2}{*}{ POLITICAL INDICATORS } & State Legitimacy \\
& Public Services \\
& Human Rights and Rule of Law \\
\hline \multirow{2}{*}{ SOCIAL AND CROSS-CUTTING INDICATORS } & Demographic Pressures \\
& Refugees and IDPs \\
& External Intervention \\
\hline
\end{tabular}

\section{Model Establishment}

\subsection{Obtaining Weight Based on Entropy Weight Method (EWM)}

Entropy weight method is an objective weighting method. It determines the weight based on the size of the information provided by the observed values of each indicator. The greater the amount of information, the less uncertainty, and the smaller entropy is, and vice versa. Entropy is used to determine the degree of dispersion of each indicator, and the impact of the comprehensive evaluation indicators of each indicator is obtained, and the weight is obtained. Since the current indicators are not uniformed, the target treatment is needed to reduce the dimension of indicators firstly. So we adopt the entropy weight method based on correlation coefficient to solve this problem. The detailed algorithm is shown as follows in Fig. 1.

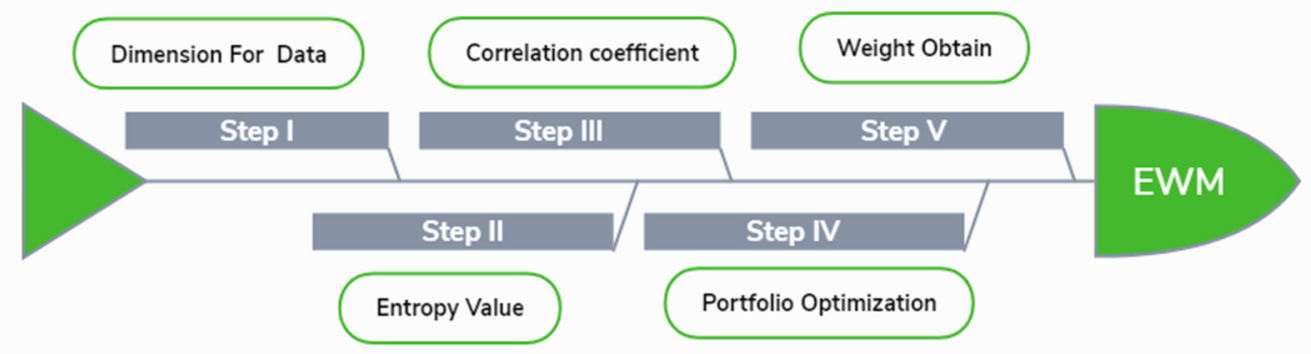

Fig. 1 Step of EWM

After 5 above steps, we get the weight of 5 second-level indicators:

$$
W=(0.3027,0.3259,0.1421,0.0642,0.1652)^{T}
$$

\subsection{Solve the Weight of Third-level Indicators}

Coefficient of variation method is the direct use of the information contained in the indicators, indicators calculated by the weight, is a method of objective empowerment. The basic approach of this method is as follows: In the evaluation index system, the bigger the index value difference is, the harder it is to achieve. Such indicators better reflect the gap between the units being evaluated. In this paper, we take the coefficient of variation coefficient to get the weight of 13 third-level indicators: 
Table 2 .States Fragility Assessment Index

\begin{tabular}{cc}
\hline Type & Indicators \\
\hline Safety Condition $(30.27 \%)$ & Security Apparatus(22\%) \\
& Military Budget $(42 \%)$ \\
Group Grievance $(36 \%)$ \\
\hline Politics Situation $(32.59 \%)$ & External Intervention(39\%) \\
Public Services $(61 \%)$
\end{tabular}

It focuses on divisions and schisms between different groups in society - particularly divisions based on social or political characteristics - and their role in access to services or resources, and inclusion in the political process.

\subsection{Model Establishment}

According to the needs of the model, we have accessed to a large amount of data and databases and obtained nearly nine years' data of 13 indicators in ten countries. First, we make the data consistent and standardized, then multiply the data of the third indicators by Weight, the value of the second-level index is obtained, and then the value of the second-level index is multiplied by the weight in succession to obtain the total index SFA used to measure the vulnerability of each country.

Then, the data of the third-level indicators of nine years in ten countries are averaged, multiplied by their weights in turn, and the values of the five second-level indicators - SC, PS, EDL, SSHD, $\mathrm{CCD}$ of ten countries are obtained. The model is fitted by Regress $(\mathrm{y}, \mathrm{x})$ function in MATLAB:

$$
f\left(x_{1}, x_{2}, x_{3}, x_{4}, x_{5}\right)=0.1560 x_{1}+0.2777 x_{2}+0.1489 x_{3}+0.1718 x_{4}+0.2456 x_{5}
$$

This is the model we use to measure national vulnerability based on the above analysis. And $x_{1}, x_{2}, x_{3}, x_{4}, x_{5}$ represent $S C, P S, E D L, S S H D, C C D, y$ represents $S F A$.

The final result of 10 countries' second-level indicators data and the SFA index shows below.

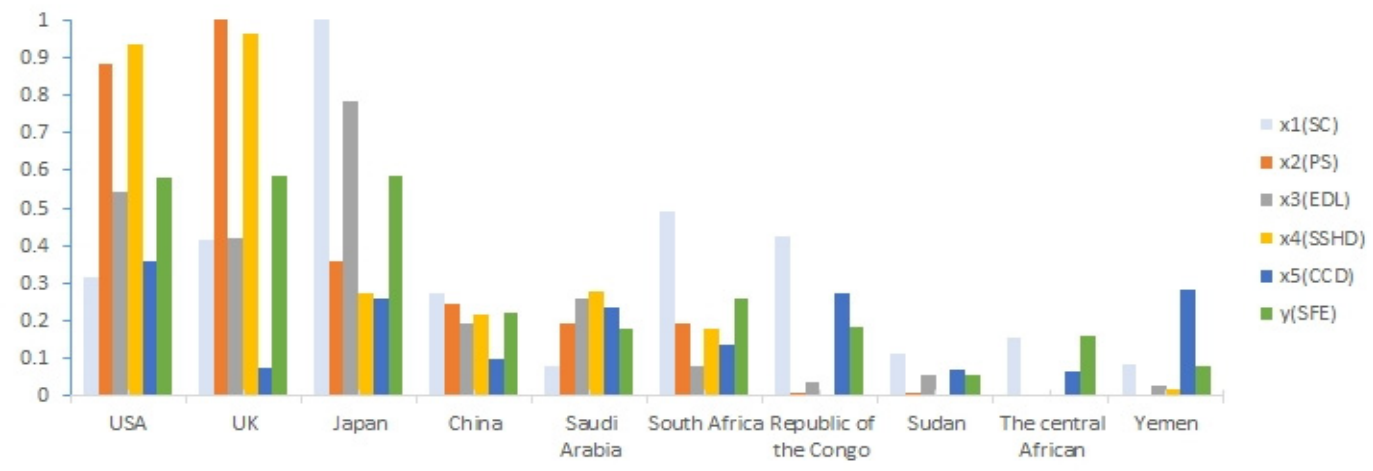

Fig. 210 Countries SFA 


\subsection{Correlation Coefficient Method for the Impact of Climate on other Indicators}

Climate refers to hot and cold, wet and dry[2], the most scientific measure of climate change is the two indicators of temperature and precipitation, we are based on 10 countries 25 years of average annual temperature and precipitation data[2], the temperature and precipitation by $1: 1$ the importance of getting a measure of climate change indicators $\mathrm{C} 1$, then according the for formula(2)

$$
\rho_{X Y}=\frac{\operatorname{Cov}(X, Y)}{\sqrt{D(X)} \sqrt{D(Y)}}
$$

Using the formula (2) to solve the correlation coefficient between climatic index and $S C, P S, E D L$, $S S H D$ and $C D$ separately, it can be obtained from the function corrcoef $(x, y)$ in MATLAB:

Table 3. Correlation Coefficient

\begin{tabular}{cccccc}
\hline & SC & PS & EDL & SSHD & CD \\
\hline$\rho_{X n Y}$ & -0.6702 & -0.6041 & -0.7388 & -0.6032 & -0.1058 \\
\hline
\end{tabular}

The above correlation coefficient can quantitatively measure the impact of climate change.

\subsection{Fragility Threshold}

In order to define the standard of fragile, moderate, or stable, we get the following threshold through the qualitative analysis according to the data in Tab.2 and the data of other countries in the world:

Table 4. Fragility Threshold

\begin{tabular}{ccc}
\hline Fragile & Moderate & Stable \\
\hline $0<\mathrm{y}<0.112$ & $0.112 \leqslant \mathrm{y}<0.39$ & $\geqslant 0.39$ \\
\hline
\end{tabular}

We randomly selected 8 countries from 197 countries and regions to conduct tests. Combined with the FSI, we judged whether they met the proposed standards, and the results were in line with expectations.

\section{Model Modification and Application}

To verify the accuracy of the model established in this paper and to test whether the model can reflect the fragility of a country in a more practical way, this paper chose Egypt as a test sample. Egypt is dry and rainless, and the climate is dry and hot. The Nile Delta and the northern coastal areas have a subtropical Mediterranean climate with a relatively mild climate.[5] The area comprises 5.5\% of the area of Egypt, but has over 95\% of its people and its agriculture. Egypt's Mediterranean coast and the Nile Delta have been identified as vulnerable to seal level rise. The rate of sea level rise for the Nile Delta ranges between $3.2-6.6 \mathrm{~mm} /$ year, coastal areas will be more vulnerable to an increasing frequency and intensity of extreme coastal storms associated with sea level rise. As with many climate change modeling outcome, regional projections at the spatial scale of the Nile Delta suggest that the southern Mediterranean has Already seen a measurable increase in the number of natural disasters: from an average of three natural disasters/year in 1980; to an average of $>15 /$ year in 2006. An increase in frequency and severity of storm surges is already evident; and the Continuation of rising seas, sinking lands, and more frequent and intense storms is a necessary inference from the review of recent trends and future climate change forecasts. [6]

The population of Egypt is huge. According to the World Bank's 2016 data, the population of Egypt has reached 97.60 million, so the impact caused by climate change will cause greater losses. 
The paper collected data on secondary indicators for Egypt for the past five years and used the SFAM to calculate the five-year SFA in Egypt. The vulnerability index in Egypt is not satisfactory, as shown in the chart below.

Table 5. Egypt Data Based on SFAM

\begin{tabular}{cccccc}
\hline & 2017 & 2016 & 2015 & 2014 & 2013 \\
\hline SC & 0.1683 & 0.1200 & 0.2765 & 0.2293 & 0.2800 \\
PS & 0.2639 & 0.1828 & 0.2371 & 0.2384 & 0.1539 \\
EDL & 0.0804 & 0.2466 & 0.1966 & 0.2334 & 0.2684 \\
SSHD & 0.1772 & 0.2618 & 0.2610 & 0.2271 & 0.2761 \\
CCD & 0.2044 & 0.1626 & 0.1891 & 0.1960 & 0.2621 \\
SFA & 0.1935 & 0.1746 & 0.2369 & 0.2272 & 0.2340 \\
\hline
\end{tabular}

The Gray Prediction Model has the advantages of simple operation, high precision, and strong sequence generation, and is suitable for predictions with less original data. The steps are as follows:

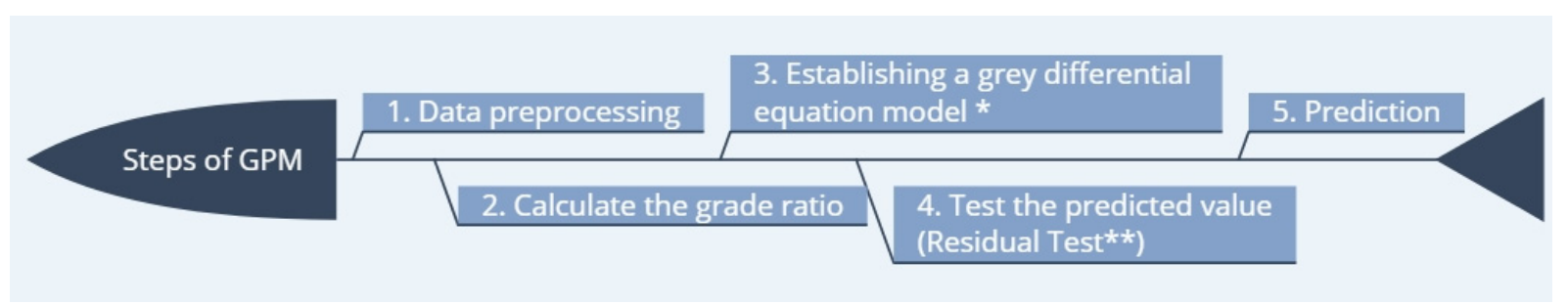

Fig. 3 Steps of GPM

In the picture above, * represents the grey differential equation:

$$
x^{(0)}(k)+\alpha z^{(1)}(k)=b, k=2,3, \cdots, n
$$

**represents the formula of Residual Test:

$$
\zeta(k)=\frac{x^{(0)}-\hat{x}^{(0)}(k)}{\hat{x}^{(0)}(k)}, k=1,2, \cdots, \text { where } \hat{x}^{(0)}(1)=x^{(0)}(1)
$$

In order to study the impact of future climate change on Egypt, this paper uses Gray Prediction Model (GM $(1,1))$ to predict SFA of the country in the next fifteen years (2018-2032) based on the SFA of the past five years. Using MATLAB, we get the line chart Fig. 4 and data Table 6 are as follows:

Table 6. Projected SFA from 2018-2032 in Egypt

\begin{tabular}{cccccc}
\hline & 2018 & 2019 & 2020 & 2021 & 2022 \\
\hline FSI & 0.1792 & 0.1697 & 0.1607 & 0.1522 & 0.1441 \\
\hline & & & & 2026 & 2027 \\
\hline FSI & 0.1364 & 0.1292 & 0.1223 & 0.1158 & 0.1097 \\
\hline & & & & \\
\hline & 2028 & 2029 & 2030 & 2031 & 2032 \\
\hline FSI & 0.1039 & 0.0983 & 0.0931 & 0.0882 & 0.0835 \\
\hline
\end{tabular}

Since the Critical Value Determined in this Paper has a Certain Degree of Volatility, it can be seen that the Fluctuation is Around 0.4. from the Results Chart Above, we can Find that the Fragility of 
the Egypt Decreases Over Time. the Value in 2026 is 0.1158 ; the Value in 2027 is 0.1097 , So the Threshold Value 0.112 of "Fragile" is Reached in 2026-2027.

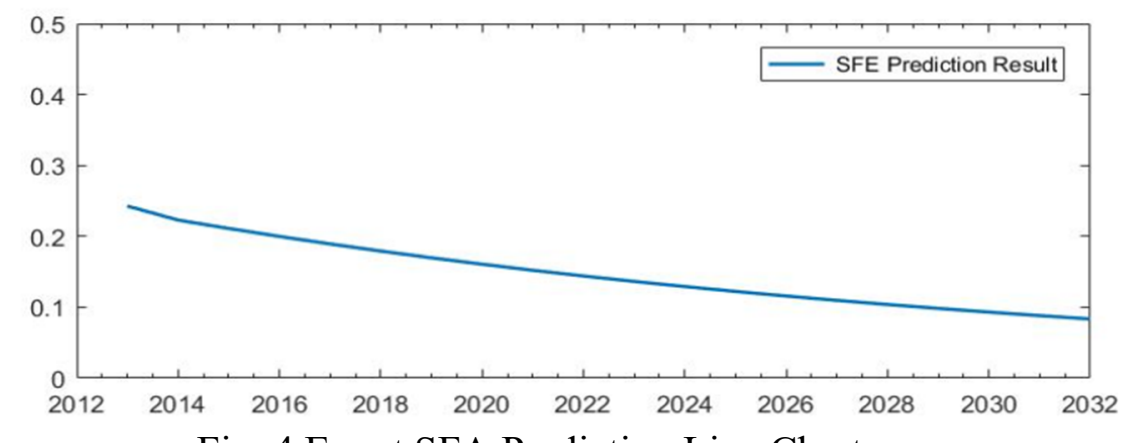

Fig. 4 Egypt SFA Prediction Line Chart

Egypt is a unique country with respect to its water resources. More than $95 \%$ of the water budget of Egypt is generated outside its territory. Although we cannot yet predict the impact of climate change on the Nile Basin, there are indications that the impacts will be significant. Any decrease in the total supply of water, coupled with the expected increase in consumption due to the high population growth rates will have drastic impacts. Water management is thus one of the most important adaptation actions. Adaptation of supply includes measures to improve rain harvesting techniques, increase abstraction of ground water, recycle water, desalinate water, improve its transportation and rationalize its use. Meanwhile, adaptation of demand requires minimizing the need for water and optimizing the economic return of its unit volume.[5].

\section{Conclusion}

Based on the Fragile States Index, this paper establishes a States Fragility Assessment model based on climate change, and takes Egypt as an example for application. Among them, the index weight is obtained by entropy weighting method, and the result is objective and credible. A grey prediction model was used for the prediction of future SFA in Egypt, and the results were highly accurate. Finally, based on the prediction results, this paper proposes effective containment measures for the future impact of climate change in Egypt. Under the premise that the region or country under study is not subject to extreme climate change in recent years, the data that SFAM needs is available and accurate, then the model can be used in a wider range to provide a reference for national and regional governments to make decisions.

\section{References}

[1]. Information on: http://fundforpeace.org/fsi/.

[2]. Xiaohui Su. Current world military spending growth [J]. International Studies, 2010 (5): 67-69.

[3]. Schwartz, P. and Randall, D. "An Abrupt Climate Change Scenario and Its Implications for United States National Security”, October 2003.

[4]. Information on: https://data.worldbank.org.cn/indicator.

[5]. Ruochen Sun: The Law and Causes of Surface Water Resources Variation with the Climate Change in Nile Basin (Master, Zhengzhou University, China 2018). p.23.

[6]. Information on: http://adaptation-undp.org/explore/northern-africa/egypt. 